\title{
Variations in the breeding system and the population genetic structure of Trillium kamtschaticum (Liliaceae)
}

\author{
MASASHI OHARA*, HARUKO TAKEDA, YOKO OHNO \& YOSHIYA SHIMAMOTO \\ Laboratory of Plant Genetics and Evolution, Faculty of Agriculture, Hokkaido University, Sapporo 060, Japan.
}

\begin{abstract}
The breeding system of Trillium kamtschaticum (Liliaceae) was investigated in 23 populations located in Hokkaido, Japan. In addition, analyses of genetic structure were made based on allozyme variation. The populations in the eastern region of Hokkaido were found to exhibit high genetic variability. Emasculated individuals in these populations produced mature seeds, whereas bagged individuals did not. By contrast, northern and southern populations mostly exhibited very low genetic variability. Based on studies of chromosome variations in natural populations of this plant, it has been predicted that inbreeding is responsible for the low levels of genetic variation observed. However, in breeding experiments, both bagged and emasculated individuals produced mature seeds. Most of the self-compatible and genetically variable populations were at Hardy-Weinberg equilibrium. These results suggest that the plants in the eastern populations are self-incompatible and that seed production and high genetic diversity result from predominant outbreeding (insect pollination). By contrast, the northern and southern populations with low genetic diversity potentially exploit a mixed system of outbreeding and inbreeding.
\end{abstract}

Keywords: breeding system, genetic variation, isozymes population structure, self-incompatibility, Trillium kamtschaticum

\section{Introduction}

Breeding systems have been recognized to have a profound influence on the extent and structure of genetic variation in plant populations. For example, outbreeding populations are expected to have greater genetic diversity, higher levels of heterozygosity, and show less differentiation among populations than self-fertilized populations (Wright, 1921; Allard et al., 1968). In practice, the population genetic structures of large numbers of species with different breeding systems have been compared and empirical support for the hypothesis that levels of genetic variation differ between inbreeding and outbreeding species has been obtained (Brown, 1979; Hamrick et al., 1979; Gottlieb, 1981; Loveless \& Hamrick, 1984; Hamrick \& Godt, 1989). For investigations of more direct effects of different breeding systems on levels of genetic diversity in

*Correspondence: Laboratory of Floriculture and Landscape Architecture, Faculty of Agriculture, Hokkaido University, Sapporo 060, Japan. plant populations, intraspecific comparisons have proved valuable. Although interspecific comparisons involve the evolutionary histories of species and subsequent variations in demography and life history characteristics, intraspecific studies allow comparisons to be made among closely related and genetically similar populations. In this context, Rick et al. (1977, 1979), Schoen (1982b), Barrett (1985), Glover \& Barrett $(1986,1987)$, and Holtsford \& Ellstrand (1989) investigated genetic variation within species that include both inbreeding and outbreeding populations, clearly demonstrating the consequences of breeding system variation on levels of genetic variation.

Trillium kamtschaticum Pall. (Liliaceae) is an Asiatic species of the genus Trillium, which is one of the representative temperate woodland elements. Trillium kamtschaticum is a diploid species $(2 n=10)$ and it is distributed mainly in Hokkaido and in northern Honshu, Japan. Comparative studies of chromosomal variations in natural populations based on structural changes in chromosomes shown by differential staining at low temperature revealed 
three geographical groups, North, East and South (Kurabayashi, 1957). Populations of the North group have high inter- and intrapopulation homogeneity. By contrast, the East group shows quite high heterogeneity. The South group is composed of populations which have high intrapopulation homogeneity. It was suggested that this intraspecific differentiation was caused by a combination of natural selection and random genetic drift associated with ancient eco-geographical changes in Hokkaido (Kurabayashi, 1957). Further, on the basis of the chromosomal variations, Fukuda $(1967,1989,1990)$ suggested that the differentiation of breeding systems (outbreeding and inbreeding) within and among populations was responsible for the different levels of genetic variation. For example, low genetic variability in a population was explained by the prevalence of an inbreeding system.

As mentioned previously, the breeding system is a major determinant of the genetic structure of a population. However, in order to identify the breeding system that prevails in a natural population, ecological studies including pollination experiments as well as observations of floral biology (morphology, physiology and phenology), are essential (Grant, 1954; Rick et al., 1977, 1979, Schoen, 1977, 1982a; Barrett, 1985; Glover \& Barrett, 1986; Morgan \& Barrett, 1989).

In this study, in order to examine whether differences in genetic structure are associated with contrasting breeding systems in populations of $T$. kamtschaticum, several ecological examinations of the mating system were conducted for 23 populations. In addition, analyses of genetic structures were carried out and phylogenetic relationships of the populations were proposed based on allozyme variation.

\section{Materials and Methods}

\section{Materials and study sites}

Trillium kamtschaticum Pall. (Liliaceae) is a herbaceous spring perennial, as are other species in the genus. More than 10 years are required for the change from vegetative to reproductive growth at which time a single flower is produced with three white petals (Samejima \& Samejima, 1962). The plant flowers in May and the flowers remain in anthesis for about a week. Trillium kamtschaticum is polycarpic and reproduces exclusively by seeds. Vegetative reproduction and clonal growth do not occur in this plant (Ohara \& Kawano, 1986).

The field study and sampling of materials were conducted at the sites of 23 populations in Hokkaido, Japan (Fig. 1, Table 1) in 1990. The study sites are broad-leaved deciduous forests, dominated mainly by Ulmus davidiana var. japonica, Fraxinus mandshurica var. japonica, Quercus mongolica var. grosseserrata and Acer mono, with the exception of the HA and NA sites, which include Cryptomeria japonica and Larix leptrepis plantations, respectively. Population size and the density of flowering plants varied among populations (Table 1).

\section{Breeding systems}

To characterize the breeding system, pollination experiments on single-flowered plants were conducted for each population. The following procedures were performed. (1) Flowers were bagged with nylon bags prior to anthesis. (2) Flowers were emasculated prior to anthesis and left in an open-pollinated condition. (3) Flowers were emasculated prior to anthesis and bagged with nets $(1 \mathrm{~mm} \times 1 \mathrm{~mm}$ mesh). This treatment was performed at six selected populations in various geographical regions, where the populations are relatively large. (4) Flowers were left in an open-pollinated condition as controls. Each treatment was applied to 25 individuals per population. At fruiting in July, all individuals in the pollination experiments were collected and the seed sets were examined. The seed-setting rate per individual [seed-ovule $(\mathrm{S} / \mathrm{O})$ ratio: ratio of total number of seeds produced per individual to total number of ovules per individual] was calculated. For statistical analysis of seed-setting rates, arcsine transformation was adopted (Sokal \& Rohlf, 1981).

\section{Electrophoretic analysis}

Leaf materials from 30 distant flowering individuals were randomly sampled in each population and stored at $-60^{\circ} \mathrm{C}$ prior to analysis by electrophoresis. For electrophoresis, the leaf materials were ground in $30 \mu \mathrm{L}$ of cold extraction buffer $(0.1 \mathrm{M}$ Tris-HCl,

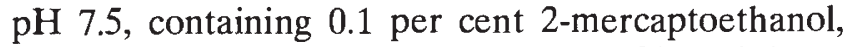
$10 \mathrm{~mm} \mathrm{KCl}, 10 \mathrm{~mm} \mathrm{MgCl}, 1 \mathrm{~mm}$ EDTA and 4 per cent PVP). The resulting slurry was absorbed by wicks of filter paper, which were inserted into a starch gel for electrophoresis. Enzymes were resolved in 12 per cent starch gels with two buffer systems. System 1 consisted of an electrode buffer of $0.065 \mathrm{M}$ L-histidine (free base) and $0.007 \mathrm{M}$ citric acid (monohydrate), adjusted to $\mathrm{pH}$ 6.5. The gel buffer consisted of threefold diluted electrode buffer (Cardy et al., 1981). In system 2, the gel buffer contained $0.033 \mathrm{M}$ Tris, $0.005 \mathrm{M}$ citric acid, $0.004 \mathrm{M}$ 


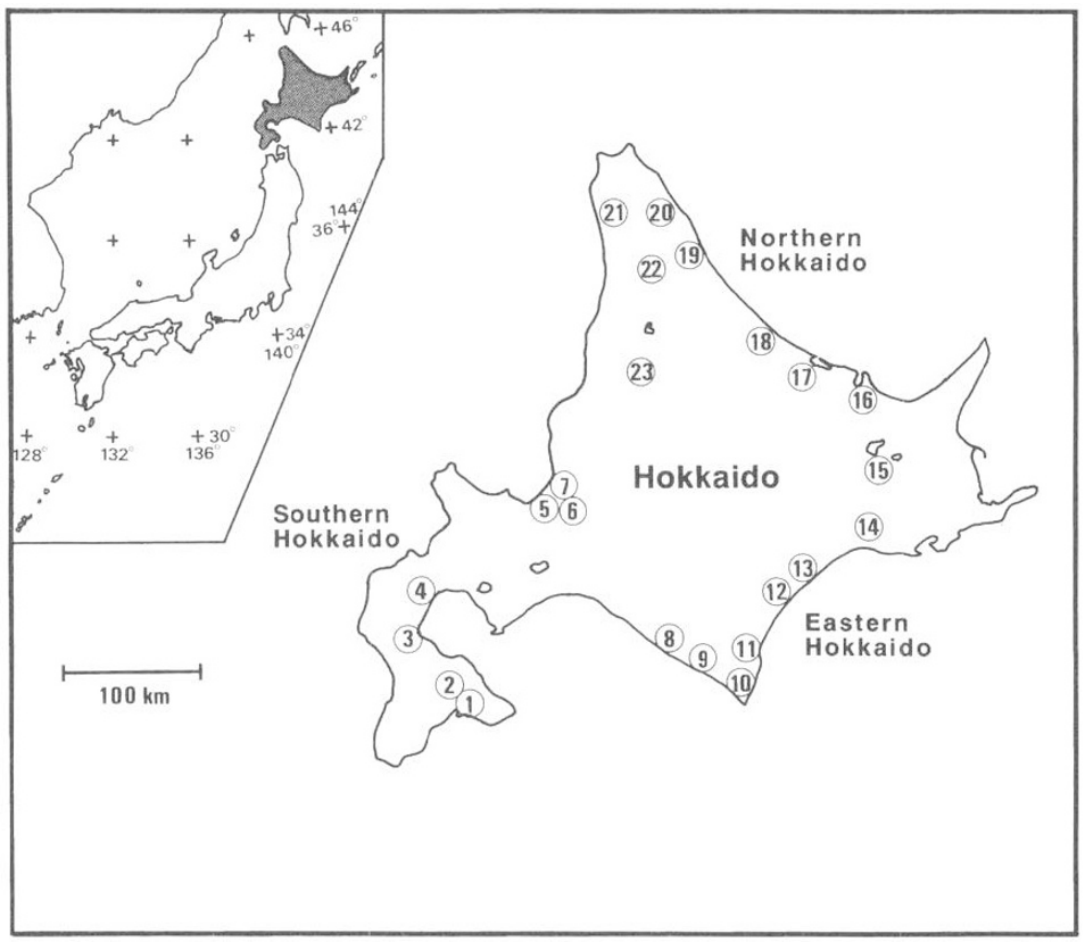

Fig. 1 Locations of the 23 populations of Trillium kamtschaticum examined in the present study. Population numbers correspond to those in Table 1. The designation of the three geographical regions is taken from the work of Kurabayashi (1957).

Table 1 Study sites and sources of Trillium kamtschaticum

\begin{tabular}{lllrr}
\hline $\begin{array}{l}\text { Population } \\
\text { no. }\end{array}$ & Population & Abbreviation & $\begin{array}{r}\text { Population } \\
\text { size }\left(\mathrm{m}^{2}\right)\end{array}$ & $\begin{array}{r}\text { Plant } \\
\text { density* }\end{array}$ \\
\hline 1 & Mt. Hakodate & HA $\dagger$ & 12000 & 102 \\
2 & Nanae & NA & 1000 & 21 \\
3 & Yakumo & YA & 300 & 14 \\
4 & Oshamanbe & OS $\dagger$ & 3600 & 59 \\
5 & Ishikari & IS & 6000 & 106 \\
6 & Nopporo & NO $\dagger$ & 2400 & 28 \\
7 & Tobetsu & TB & 1200 & 34 \\
8 & Shizunai & SZ & 800 & 62 \\
9 & Urakawa & UR & 40000 & 40 \\
10 & Erimo & ER & 450 & 12 \\
11 & Hiroo & HI $\dagger$ & 50000 & 128 \\
12 & Yudounuma & YU & 10500 & 87 \\
13 & Urahoro & UH & 7200 & 73 \\
14 & Shimohororo & SH & 6400 & 13 \\
15 & Teshikaga & TE & 4500 & 68 \\
16 & Yobito & YO $\dagger$ & 24000 & 113 \\
17 & Saroma & SA & 4800 & 78 \\
18 & Monbetsu & MN & 360 & 18 \\
19 & Esashi & ES & 2400 & 28 \\
20 & Hamatonbetsu & HT & 1050 & 57 \\
21 & Toyotomi & TY & 270 & 13 \\
22 & Sakkuru & SK $\dagger$ & 12000 & 66 \\
23 & Shintomi & ST & 4800 & 35 \\
\hline
\end{tabular}

*Average numbers of plants in $25 \mathrm{~m}^{2}$ were calculated by randomly placing a $5 \times 5 \mathrm{~m}$ quadrat five times within each population.

$\ddagger$ Populations at which a pollination experiment, i.e. emasculation and bagging with nets, was conducted. 
lithium hydroxide and $0.03 \mathrm{~m}$ boric acid with the $\mathrm{pH}$ adjusted to 7.6 and the electrode buffer consisted of $0.039 \mathrm{M}$ Tris and $0.263 \mathrm{~m}$ boric acid with the $\mathrm{pH}$ adjusted to 8.0 (Soltis \& Soltis, 1987).

System 1 was employed to resolve isozymes of aconitate hydratase (ACO; EC 4.2.1.3), malate dehydrogenase (MDH; 1.1.1.37), phosphoglucomutase (PGM; 5.4.2.2), phosphoglucoisomerase (PGI; 5.3.1.9) and isocitrate dehydrogenase (IDH; 1.1.1.42). System 2 resolved isozymes of leucyl aminopeptidase (LAP; 3.4.11.1), esterase (EST; 3.1.1.2) and glutamatic-oxaloacetatic transaminase (GOT; 2.6.1.1). Staining procedures were taken from Soltis et al. (1983). Genetic interpretations of banding patterns were inferred from segregation patterns with reference to typical subunit structures (Gottlieb, 1981, 1982; Crawford, 1983).

Standard genetic diversity statistics, including percent of polymorphic loci $(P)$, mean number of alleles per polymorphic locus $\left(A_{\mathrm{p}}\right)$, mean number of alleles per locus $(A)$, and observed heterozygosity were calculated. In addition, the expected level of heterozygosity for each population was also calculated. The $F$ values or fixation index (Wright, 1951) were calculated and tested for significant deviation from Hardy-Weinberg equilibrium using chi-squared tests.

The distribution of genetic variation within and among populations was analysed by application of Nei's (1973) gene diversity statistics [total gene diversity $\left(H_{\mathrm{T}}\right)$, gene diversity within sites $\left(H_{\mathrm{S}}\right)$ and differentiation among sites $\left(G_{\mathrm{ST}}\right)$ ]. Genetic identities and distances were computed for pair-wise comparisons of populations (Nei, 1972), and a dendrogram was generated, based on the distance matrix by the UPGMA method (Sneath \& Sokal, 1973).

\section{Results}

\section{Breeding systems}

The results of pollination experiments conducted at each site are represented in Fig. 2. The YA, SZ and SH populations are not included because the treated plants were accidentally damaged by weeding before seed maturation. Trillium kamtschaticum has an average of $225.1 \pm 39.8( \pm S D)$ ovules per flower (Ohara \& Kawano, 1986). Average seed-setting rates ( $\mathrm{S} / \mathrm{O}$ ratios) of naturally pollinated individuals varied among populations from 38.1 per cent (ST) to 81.7 per cent (IS).

Bagged individuals produced mature seeds in all of the northern and southern populations examined, suggesting that the plants in these populations were self-compatible and also that substantial self-pollination had occurred. Furthermore, the average seedsetting rates were not significantly different from those of naturally pollinated individuals, except in the OS, YO and SA populations (Tukey-Kramer tests; Sokal \& Rohlf, 1981). By contrast, at UR, HI, YU and UH, which are located in eastern Hokkaido, individuals with bagged flowers did not produce any seeds at all, although we confirmed pollen deposition on stigmas. In other words, selffertilization did not occur in these four populations. It is noteworthy, however, that among the eastern populations, the plants at ER exhibited self-compatibility and the average seed-setting rate of the bagged plants did not differ significantly from that of naturally pollinated plants.

Plants emasculated prior to anthesis produced mature seeds in all populations examined, suggesting that substantial outbreeding occurs in T. kamtschaticum. Although the average seed-setting rates varied from 32.7 per cent (ES) to 75.3 per cent (IS), the values did not differ significantly from the average seed-setting rates of open-pollinated individuals except at NA, ER, YO, MN and TY, where seedsetting rates were lower than those of open pollinated plants. Plants in six populations that had been emasculated prior to anthesis and bagged with net produced no seeds or, if seeds were produced, seedsetting rates were extremely low. Although this experiment was not carried out with all populations, these results, obtained from relatively large populations with high plant density, suggest that seed production by wind pollination does not generally occur. That is, the seeds obtained from the plants that had been emasculated and left under open pollination were the result of insect pollination. Furthermore, seeds sets of naturally pollinated plants in four eastern populations (UR, HI, YD and $\mathrm{UH}$ ), in which self-fertilization was not observed, were the result of insect pollination.

\section{Genetic diversity}

Thirteen putative isozymes were clearly and consistently resolved, including one locus for IDH, PGM, LAP, PGI, MDH, two for ACO, and three for EST and GOT. In the case of EST, one additional zone of activity was observed, but it was not scored because of poor resolution. Of the 13 loci examined, eight loci were monomorphic for all populations. Variation was observed at the other five loci, Aco-1, Mdh-1, Pgi, Est-2, Got-2, namely, at 38 per cent of all loci scored. Allele frequencies are available on request. 


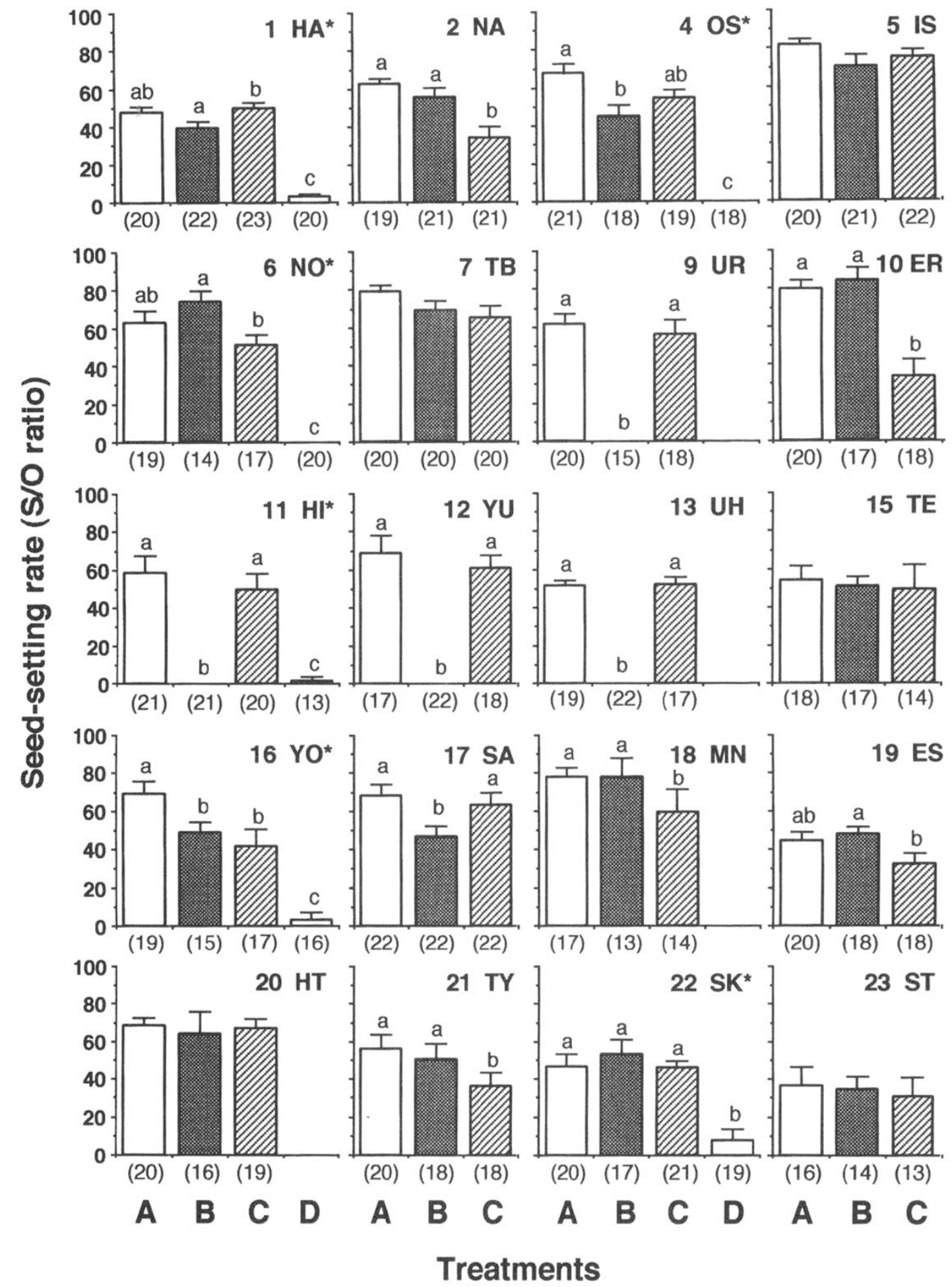

Fig. 2 Mean seed-setting rates (S/O ratios) obtained from the various pollination experiments conducted with each population of Trillium kamtschatium. Bars represent standard errors of the mean. (A) Controls, (B) plants bagged with nylon bags prior to anthesis, (C) plants emasculated prior to anthesis, (D) plants emasculated prior to anthesis and bagged with nets. Of 25 plants treated, the number of plants collected for each treatment at the fruiting stage is shown in parentheses. Results of treatments with different lower case letters were found to be significantly different (TukeyKramer tests, $P<0.05$; Sokal and Rohlf, 1981). Population numbers and abbreviations correspond to those in Table 1. ${ }^{*}$ Populations for which the pollination experiment (D) was conducted. 
Table 2 Measures of genetic variation among 23 populations of Trillium kamtschaticum

\begin{tabular}{|c|c|c|c|c|c|c|c|}
\hline $\begin{array}{l}\text { Population } \\
\text { no. }\end{array}$ & Population & $P$ & $A_{\mathrm{p}}$ & $A$ & $\begin{array}{c}\text { Observed } \\
\text { heterozygosity }\end{array}$ & $\begin{array}{c}\text { Expected } \\
\text { heterozygosity }\end{array}$ & $F$ \\
\hline 1 & HA & 7.69 & 2.00 & 1.08 & 0.054 & 0.036 & $-0.504^{*}$ \\
\hline 2 & NA & 7.69 & 2.00 & 1.08 & 0.006 & 0.006 & -0.034 \\
\hline 3 & YA & 15.38 & 2.00 & 1.15 & 0.035 & 0.039 & 0.091 \\
\hline 4 & OS & 0 & 0 & 1.00 & 0 & 0 & - \\
\hline 5 & IS & 0 & 0 & 1.00 & 0 & 0 & - \\
\hline 6 & NO & 7.69 & 2.00 & 1.08 & 0.008 & 0.008 & -0.067 \\
\hline 7 & TB & 7.69 & 2.00 & 1.08 & 0.004 & 0.004 & -0.053 \\
\hline 8 & SZ & 15.38 & 2.00 & 1.15 & 0.062 & 0.064 & 0.036 \\
\hline 9 & UR & 15.38 & 2.00 & 1.15 & 0.054 & 0.048 & -0.137 \\
\hline 10 & ER & 30.77 & 2.25 & 1.38 & 0.059 & 0.068 & 0.137 \\
\hline 11 & HI & 30.77 & 2.50 & 1.46 & 0.092 & 0.100 & 0.080 \\
\hline 12 & YU & 30.77 & 2.50 & 1.46 & 0.150 & 0.125 & -0.205 \\
\hline 13 & UH & 30.77 & 2.25 & 1.38 & 0.125 & 0.118 & -0.057 \\
\hline 14 & SH & 30.77 & 2.50 & 1.46 & 0.128 & 0.120 & -0.066 \\
\hline 15 & $\mathrm{TE}$ & 0 & 0 & 1.00 & 0 & 0 & - \\
\hline 16 & YO & 0 & 0 & 1.00 & 0 & 0 & - \\
\hline 17 & SA & 0 & 0 & 1.00 & 0 & 0 & - \\
\hline 18 & MN & 0 & 0 & 1.00 & 0 & 0 & - \\
\hline 19 & ES & 0 & 0 & 1.00 & 0 & 0 & - \\
\hline 20 & HT & 7.69 & 2.00 & 1.08 & 0.012 & 0.014 & 0.130 \\
\hline 21 & TY & 0 & 0 & 1.00 & 0 & 0 & - \\
\hline 22 & SK & 0 & 0 & 1.00 & 0 & 0 & - \\
\hline \multirow[t]{2}{*}{23} & ST & 7.69 & 2.00 & 1.08 & 0.046 & 0.039 & -0.176 \\
\hline & Mean & 10.70 & 1.30 & 1.13 & 0.036 & 0.034 & -0.060 \\
\hline
\end{tabular}

${ }^{*} P<0.05$.

$P$, percentage of polymorphic loci; $A_{\mathrm{p}}$, number of alleles per polymorphic locus; $A$, number of alleles per locus; $F$, fixation index.

The measures of genetic variation are given in Table 2 . The percentage of loci that were polymorphic varied among populations, ranging from 0 per cent (OS, IS, TE, YO, SA, MN, ES, TY and SK) to 31 per cent (ER, HI, YU, UH and SH) with a mean of 11 per cent. Most of the northern populations were monomorphic for all loci. The mean number of alleles per polymorphic locus was 1.30 , with the populations with larger numbers of variable loci (ER, HI, YU, UH and $\mathrm{SH}$ ) having large numbers of alleles per polymorphic locus $(2.25-2.50)$. The mean number of alleles per locus was 1.13 , ranging from 1.00 to 1.46 . Mean observed heterozygosity $(0.036)$ was slightly higher than the expected heterozygosity (0.034) but did not deviate significantly from the expected heterozygosity. The $F$ values also indicate that genetically variable populations are at HardyWeinberg equilibrium except population HA and most of those populations show negative fixation indices, indicating an excess of heterozygotes.

Genetic diversity statistics were calculated for all
13 loci examined and the mean values are $H_{\mathrm{T}}=0.051, \quad H_{\mathrm{S}}=0.034$ and $G_{\mathrm{ST}}=0.097$. These values indicated that the overall level of allozyme variation was low in $T$. kamtschaticum. The low $G_{\mathrm{ST}}$ value indicates that the majority of genetic variation is located within populations; such a low $G_{\mathrm{ST}}$ is consistent with the high mean genetic identity (0.984). The highest genetic identity was found among northern populations which did not show any variation $(I=1.00)$. The lowest genetic identity was found between HA and SH (0.941). Although the populations examined showed relatively high genetic identity, clustering of populations on a UPGMA phenogram on the basis of Nei's genetic distance revealed at least two major population groups (Fig. 3 ). Most of the populations located in the eastern region formed one group except population ST. These populations had higher percentages of polymorphic loci and higher genetic diversities (cf. Table 2 ). The remaining major group consisted of northern and southern populations and was charac- 


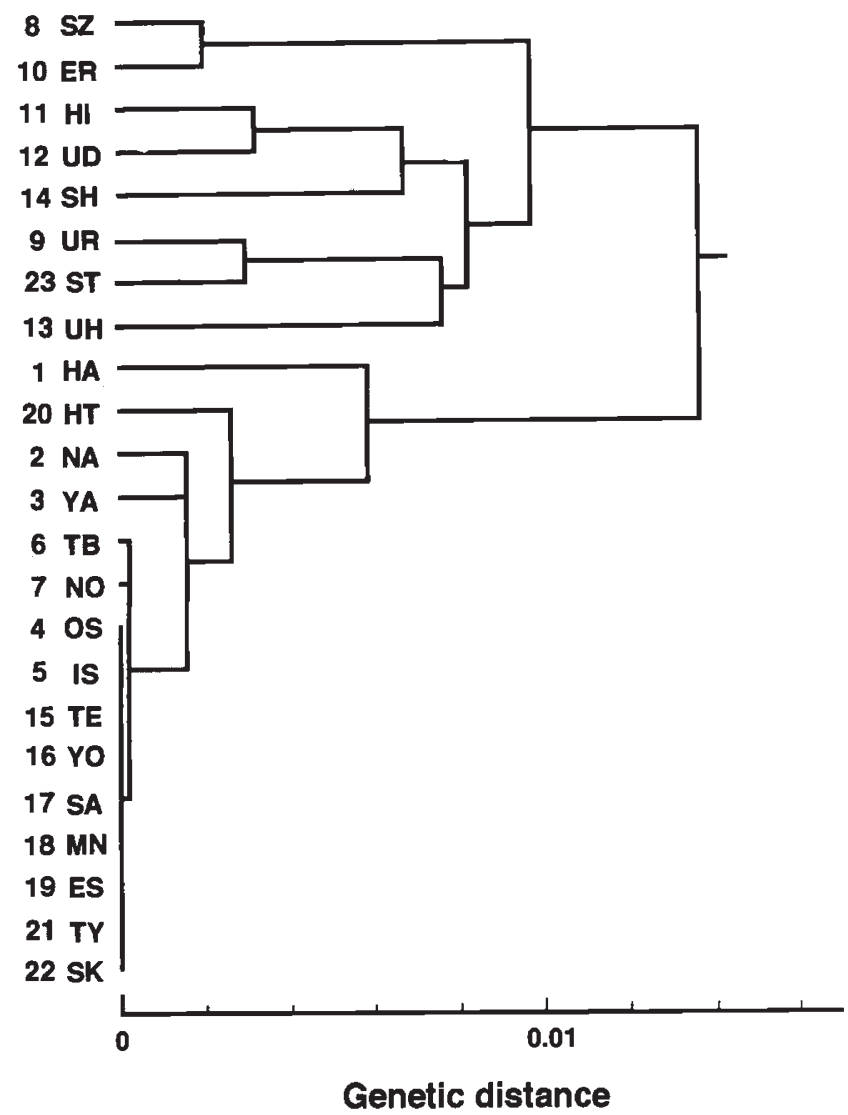

Fig. 3 Phenogram derived by UPGMA clustering from a matrix of pair-wise comparisons of Nei's genetic distances for 23 populations of Trillium kamtschaticum. Population numbers and abbreviations correspond to those in Table 1.

terized by lower percentages of polymorphic loci and lower genetic diversities.

\section{Discussion}

The overall trends in genetic variation based on allozyme variation coincided more or less with the results obtained from an analysis of chromosome composition (Kurabayashi, 1957). Thus, eastern populations show high genetic diversity, whereas northern and southern populations show much lower genetic diversity. In particular, the northern populations demonstrated very high homogeneity. It has been predicted that populations of T. kamtschaticum with a high degree of homogeneity with respect to chromosome composition depend on inbreeding (Fukuda, 1967, 1989, 1990). It is shown in this study that most of the eastern populations of T. kamtschaticum, which exhibit higher genetic diversity, are not self-pollinating and all seeds result from outbreeding arising from insect pollination. Although T. kamtschaticum does not produce nectar, the base petals have a sweet scent (Ohara, personal observation). Field observations also indicate that T. kamtschaticum is generally visited by insects belonging to the Hymenoptera (Bombus hypocrita sapporensis), the Coleoptera (e.g., Carpophilus chalybeus and Aphthonaltia angustata) and the Diptera (e.g., Scatophaga stercoraria and Melanostoma scalare) (Fukuda 1961, 1989; Ohara et al., 1991). Furthermore, bagging treatment after emasculation and crossing (direct cross- and self-pollination) experiments, using materials sampled at each population and transplanted to the Botanical Garden, Hokkaido University, showed no evidence of apomixis and dichogamy and confirmed that these eastern populations exhibit self-incompatibility. The type of self-incompatibility (gametophytic or sporophytic), however, remains unknown.

In contrast to the eastern populations, many of the populations that showed very little allozyme variation exhibited self-compatibility. However, plants emasculated prior to anthesis also produced numbers of mature seeds, suggesting that, although these populations with low genetic diversity have a substantial ability to self-pollinate, they may also be functionally outcrossing under natural conditions. In fact, most of the genetically variable and selfcompatible populations were at Hardy-Weinberg equilibrium. Therefore, low genetic diversity might not always be associated with inbreeding in $T$. kamtschaticum.

Well documented examples of the differentiation of self-compatible and self-incompatible populations within single species are provided by Leavenworthia crassa and L. alabamica (Rollins, 1963; Lloyd, 1965; Solbrig, 1972; Solbrig \& Rollins, 1977). Lloyd (1965) demonstrated that self-compatible and self-pollinating races were derived from self-incompatible progenitors that had invaded a new habitat. These sites were less favourable for pollinating bees, so that the paucity of pollinators selected for self-compatible plants within these populations. Furthermore, selfcompatible populations have developed adaptations in floral morphology (e.g. a change from extrose to introse anthers, small flower size, a decrease in the pollen-ovule ratio: $\mathrm{P} / \mathrm{O}$ ratio) that increase the efficiency of self-pollination. Rollins (1963) and Solbrig \& Rollins (1977) found that populations of selfincompatible plants were much larger than populations of self-compatible plants. Rick et al. (1979) also identified morphological and ecological differentiation between self-compatible and self-incompatible populations of Lycopersicon hirsutum. 
In T. kamtschaticum, Samejima (1958) examined morphological characteristics, such as sizes of petal, leaf, sepal, fruit and stomata, of plants from natural populations. The petals associated with attraction of pollinators were largest and widest in eastern populations and smaller and narrower in northern and southern populations. Our examinations using materials transplanted to the Botanical Garden also suggest that the eastern self-incompatible populations have large, showy flowers with longer anthers, higher pollen production and higher $\mathrm{P} / \mathrm{O}$ ratios (Ohara, unpublished data and manuscript in preparation). As summarized by Wyatt (1988), petal size and anther size appear to change with a shift from predominant selfing to predominant outcrossing and vice versa. Accordingly, the self-incompatible eastern populations seem to exhibit xenogamous floral characteristics. Furthermore, the larger population size and the higher plant density of these populations (cf. Table 1) should maintain the prevailing self-incompatibility and outcrossing systems (Rollins, 1963; Solbrig \& Rollins, 1977).

Among the self-compatible populations of $T$. kamtschaticum, some populations are isolated, having small population size and low plant density (e.g., NA, ER, MN, and TY; see Table 1). Although both self- and cross-pollination could potentially contribute to seed-set, autogamy might be favoured over xenogamy in these populations. In fact, although mature seeds were obtained from the plants that had been emasculated prior to anthesis, average seed-setting rates of these plants were significantly lower than those of both naturally pollinated and bagged plants (see Fig. 2). Furthermore, it is very important to recall that, although most of the eastern populations exhibited self-incompatibility, a small marginal population near Erimo Cape (ER) exhibited self-compatibility, and the seed-setting rate of emasculated plants was also significantly lower than those of both naturally pollinated and bagged plants.

For outcrossing of entomophilous plants, population size and plant density are closely associated with the attraction and activity of pollinators and should have a significant influence on reproductive success. For instance, population bottlenecks associated with demographic stochasticity or colonization events may bring about reduction in effective population size and promote drift (Crow, 1954). If pollinator abundance is also reduced, self-pollinating genotypes may leave more offspring than outcrossers, and reduce genetic variability. Accordingly, survival of such bottlenecks may be enhanced by self-compatibility and high levels of self-fertilization.
In fact, higher rates of self-fertilization are often found in geographically and/or ecologically marginal populations (Rick et al., 1977; Brown et al., 1978; Schoen, 1982a; Holtsford \& Ellstrand, 1989). Fukuda (1990) has also pointed out the possibility of the development of an inbreeding mating system in small, geographically marginal populations of $T$. kamtschaticum.

In order to determine the contribution of self- and out-crossing to the seed-set of naturally pollinated plants in self-compatible populations, detailed studies of ecological and geographical backgrounds of the populations, of the abundance and activity of pollinators and of phenological characteristics, such as the degree of protandry, must be performed.

\section{Acknowledgements}

The authors are grateful to Dr J. Abe and Dr T. Yahara for their guidance and helpful advice in the isozyme study. Our cordial thanks are due to Dr Y. Sano for valuable comments on the manuscript. This work was supported in part by grants no. 03740329, no. 02304008 and no. 319 (priority area, project 'Symbiotic Biosphere: an Ecological Interaction Network Promoting the Coexistence of Many Species'), from the Ministry of Education, Science and Culture of Japan, and by the Naito Foundation. Thanks are also due to two anonymous referees for their constructive criticisms, by which the present paper was much improved.

\section{References}

Allard, R. W., JAIN, S. K. AND WORKMAN, P. L. 1968. The genetics of inbreeding species. Adv. Genet., 14, 55-131.

BARRETT, S. C. H. 1985. Floral trimorphism and monomorphism in continental and island populations of Eichhomia paniculata (Spreng.) Solms. (Pontederiaceae). Biol. J. Linn. Soc., 25, 449-510.

BRown, A. H. D. 1979. Enzyme polymorphism in plant populations. Theor. Pop. Biol., 15, 1-42.

BROWN, A. H. D., ZOHARY, D. AND NEVO, E. 1978. Outcrossing rates and heterozygosity in natural populations of Hordeum spontaneum Koch in Israel. Heredity, 41, 49-62.

CARDY, B. J., STUBER, C. W. AND GOODMAN, M. M. 1981. Techniques for starch gel electrophoresis of enzyme from maize (Zea mays L.). Inst. Stat. Mimeogr. Ser. No. 1317, North Carolina State University, Raleigh.

CRAWFORD, D. J. 1983. Phylogenetic and systematic inferences from electrophoretic studies. In: Tanksley, S. D and Orton, T. J. (eds) Isozymes in Plant Genetics and Breeding, Part A, pp. 257-287. Elsevier, Amsterdam. 
CROW, J. F. 1954. Breeding structure of populations. II. Effective population number. In: Bancroft, T. A., Gown, J. W., Lush, J. L. (eds) Statistics and Mathematics in Biology, pp. 543-556. Iowa State University Press. Ames.

FUKUDA, 1. 1961. On insects visiting Trillium flowers. Essays and Studies of Tokyo Woman's Christian College, 12, 23-34, (in Japanese with English summary).

FUKUDA, I. 1967. The formation of subgroups by the development of inbreeding systems in a Trillium population. Evolution, 21, 141-147.

FUKUDA, 1. 1989. Chromosome variation and evolution in American and Asian Trillium species. In: Bock, J. H. and Linhart, Y. B. (eds) The Evolutionary Ecology of Plants, pp. 85-97. Westview Press, Boulder, CO.

FUKUDA, 1. 1990. Breeding systems in American and Asian Trillium species by means of chromosome analyses. $P l$. Sp. Biol., 5, 65-72.

GLOVER, D. E. AND BARRETT, s. C. H. 1986. Variation in the mating system of Eichhornia paniculata (Spreng.) Solms. (Pontederiaceae). Evolution, 40, 1122-1131.

GLOVER, D. E. AND BARRETT, s. C. H. 1987. Genetic variation in continental and island populations of Eichhornia paniculata (Pontederiaceae). Heredity, 59, 7-17.

GOTTL1EB, L. D. 1981. Electrophoretic evidence and plant populations. Progr. Phytochem., 7, 1-45.

GOTTL1EB, L. D. 1982. Conservation and duplication of isozymes in plants. Science, 216, 373-380.

GRANT, V. 1954. Genetic and taxonomic studies in Gilia. IV. Gilia achilleaefolia. Aliso, 3, 1-18.

HAMRICK, J. L. AND GODT, M. J. W. 1989. Allozyme diversity in plant species. In: Brown, A. H. D., Clegg, M. T., Kahler, A. L. and Weir, B. S. Plant Population Genetics, Breeding and Genetic Resources, pp. 43-63. Sinauer Associates, Sunderland, MA.

HAMRICK, J. L., LINHART, Y. B. AND MITTON, J. B. 1979. Relationship between life history characteristics and electrophoretically detectable genetic variation in plants. Ann. Rev. Ecol. Syst., 10, 173-200.

HOLTSFORD, T. P. AND ELLSTRAND, N. C. 1989. Variation in outcrossing rate and population genetic structure of Clarkia tembloriensis (Onagraceae). Theor. Appl. Genet., 78, 480-488.

KURABAYASH1, M. 1957. Evolution and variation in Trillium IV. Chromosome variation in natural populations of Trillium kamtschaticum Pall. Jpn. J. Bot., 16, 1-45.

LLOYD, D. G. 1965 Evolution of self-compatibility and racial differentiation in Leavenworthia (Cruciferae). Contr. Gray Herb., 195, 3-134.

LOVELESS, M. D. AND HAMRICK, J. L. 1984. Ecological determinants of genetic structure in plant populations. Ann. Rev. Ecol. Syst., 15, 65-95.

MORGAN, M. T. AND BARRETT, s. C. H. 1989. Reproductive correlates of mating system variation in Eichhornia paniculata (Spreng.) Solms. J. Evol. Biol., 2, 183-203.

NEI, M. 1972. Genetic distance between populations. Am. Nat., 106, 283-292.

NEI, M. 1973. Analysis of gene diversity in subdivided populations. Proc. Natl. Acad. U.S.A., 70, 3321-3323.

OHARA, M. AND KAWANO, s. 1986. Life history studies on the genus Trillium (Liliaceae) I. Reproductive biology of four Japanese species. Pl. Sp. Biol., 1, 35-45.

ohara, m., OKAZAKI, K. AND KaWAno, s. 1991. Predominant inbreeding and resource limitation in four Japanese Trillium species. Miyabea, 1, 21-30.

R1CK, C. M., FOBES, J. F. AND HOLLE, M. 1977. Genetic variation in Lycopersicon pimpinellifolium: evidence of evolutionary changes in mating systems. Pl. Syst. Evol., 127, 139-170.

RICK, C. M., FOBES, J. F. AND TANKSLEY, S. D. 1979. Evolution of mating system in Lycopersicon hirsutum as deduced from genetic variation in electrophoretic and morphological characters. Pl. Syst. Evol., 132, 270-298.

ROLLiNS, R. C. 1963. The evolution and systematics of Leavenworthia (Cruciferae). Contr. Gray Herb., 192, 3-198.

SAmejımA, K. 1958. Evolution and variation in Trillium. II. Variation in some external characters observed in natural populations of Trillium kamtschaticum Pall. Evolution, 12, 63-71.

SAMEjImA, J. AND SAMEJIMA, K. 1962. Studies on the eastern Asiatic Trillium (Liliaceae). Acta Horti Gothob., 25, 157-257.

SCHOEN, D. J. 1977. Morphological, phenological and pollen-distribution evidence of autogamy and xenogamy in Gilia achilleifolia (Polemoniaceae). Syst. Bot., 2, 280-286.

SCHOEN, D. J. 1982a. The breeding system of Gilia achilleifolia: variation in floral characteristics and outcrossing rate. Evolution, 36, 352-360.

SCHOEN, D. J. 1982b. Genetic variation and the breeding system of Gilia achilleifolia. Evolution, 36, 361-370.

SNEATH, P. H. AND SOKAL, R. R. 1973. Numerical Taxonomy: The Principles and Practice of Numerical Classification. W.H. Freeman, San Francisco.

SOKAL, R. R. AND ROHLF, F. J. 1981. Biometry, 2nd edn. W.H. Freeman, San Francisco.

SOLBRIG, O. T. 1972. Breeding system and genetic variation in Leavenworthia. Evolution, 26, 155-160.

SOlBRIG, O. T. AND ROLLiNS, R. C. 1977. The evolution of autogamy in species of the mustard genus Leavenworthia. Evolution, 31, 265-281.

SOLT1S, P. S. AND SOLTIS, D. E. 1987. Population structure and estimates of gene flow in the homosporous fern Polystichum munitum. Evolution, 41, 620-629.

SOLTIS, D. E., HAUFLER, C. H., DARROW, D. C. AND GASTONY, G. J. 1983. Starch gel electrophoresis of ferns: a compilation of grinding buffers, gel and electrode buffers, and staining schedules. Am. Fern J., 73, 9-27.

WRIGHT, s. 1921. Systems of mating. Genetics, 6, 111-178.

WRIGHT, s. 1951. The genetical structure of populations. Ann. Eugen., 15, 323-354.

WYATT, R. 1988. Phylogenetic aspects of the evolution of self-pollination. In: Gottlieb, L. D. and Jain, S. K. (eds) Plant Evolutionary Biology, pp. 109-131. Chapman and Hall, New York. 